\title{
Open Tuberculosis in Police Custody Suites, the Risks to those Working there and Current United Kingdom Public Health Legislation
}

\section{Robert M. Bruce-Chwatt*}

MFTM RCPS (Glasg), DFFP, part 1 DMJ, Senior Forensic Medical Examiner (FME), Metropolitan Police, London, UK

\begin{abstract}
There are at present 1.7 billion people worldwide infected with Mycobacterium tuberculosis and 1.7 million die every year. In the UK tuberculosis not yet endemic, but cases have doubled in the last 10 years to more than 9,000 in 2010. The main source of TB being from the immigrants and asylum seekers, both legal and clandestine, who come to the UK in ever increasing numbers. They are often seen by forensic medical examiners (FMEs) following arrest. The detainees present a problem of diagnosis and risk management for all in the custody system. Despite TB being the most common cause of illness and death among people with HIV and Aids in the European region, very few co-ordinates the treatment of the co-infection properly, due to poor patient chemo-compliance and rising costs.
\end{abstract}

\section{Introduction}

"Europe is lagging behind in the fight against tuberculosis and in 2005 there were 445,000 known new cases of TB and 66,000 deaths related to the disease in the WHO European region. The countries of the former Soviet Union account for $72 \%$ of all cases. TB is soaring in migrants, homeless people, prisoners and other socially vulnerable groups.” Peter Moszynski, BMJ ${ }^{1}$.

There are at present 1.7 billion people world wide infected with Mycobacterium tuberculosis and 1.7 million die every year [1]. In the United Kingdom, TB is not yet endemic and the main source of TB, a droplet infection by inhalation or ingestion from "open" cases, is from the immigrants, asylum seekers and clandestine or illegals, who have come and are coming to the UK in ever increasing numbers. There is also the much rarer risks of "congenital" or placental TB and dermal inoculation - verruca necrogenica. The risks of infection are determined by; dose and virulence of the TB strain, host resistance and occupation, plus the environmental atmosphere of that occupation. In the UK screening for TB is missing $70 \%$ of infections and thus far, failing to prevent the worrying rise by $50 \%$ over the last 10 years. The use of an airport screening chest $\mathrm{x}$-ray to identify cases of active TB cannot spot the symptomless carriers who represent the iceberg-belowthe-water line. The number of cases of TB in the UK last year, 2010, was in excess of 9,000. Recent secondary screenings in three large UK towns showed levels of $20 \%$ in those from the Indian subcontinent and $30 \%$ from sub-Saharan Africa that had been missed earlier [2]. Further, more rigorous, immigration TB checks are one way to try to control the problem. Despite TB being the most common cause of illness and death among people with HIV/Aids in the European region, very few co-ordinate the treatment of the co-infection properly, mainly due to poor patient chemo-compliance and rising costs of both the drugs and staffing of clinics to encourage proper compliance.

\section{Case History}

On 17/10/2003 at 10:01 hours AV, a male Angolan clandestine aged 43, was seen at a South London Police Station with his consent at the request of the Police, to establish the presence of injury and that of fitness to detain and interview. There was an allegation of immigration offences. He said that he had been in the UK for 15 years, but this seemed unlikely for a number of reasons, including the poorness of his English. He said that he suffered from TB and had been receiving treatment for this and had been taking "lots of antibiotics for six weeks", but was no longer taking them. His compliance was, therefore, very poor to non-existent and certainly not atypical. Some patients have even admitted to sending their medication back to their relatives in their country of origin; this does not bear thinking about in terms of ineffective dosage and frequency making chemo-resistance almost inevitable and world-wide.

He was otherwise fit and well, but abused Class A (MoDA 1971) drugs, namely diamorphine and cocaine. On further questioning he admitted smoking "two $£ 10.00$ Joeys" or a total of 0.4 gm of heroin daily. He took crack cocaine as well, but had "not done so for a month". His claim not to have used crack cocaine that recently was most probably untrue. His pupils, BP and pulse were normal, but he showed all the signs of post-crack binge recovery, falling asleep every few seconds, but roused very easily (Figure 1).

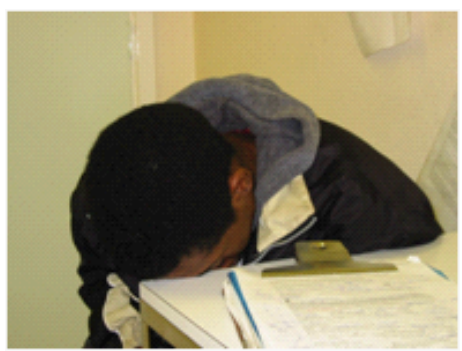

Figure 1: Prisoner asleep, head on desk; clip-board with pro-forma in the foreground.

${ }^{*}$ Corresponding author: Dr. Robert M. Bruce-Chwatt, MBBS (Lond.), MFTM RCPS (Glasg), DFFP, part 1 DMJ, Senior Forensic Medical Examiner (FME) Metropolitan Police, London, UK, E-mail: robert@bruce-chwatt.fsnet.co.uk

Received May 23, 2011; Accepted June 15, 2011; Published June 23, 2011

Citation: Bruce-Chwatt RM (2011) Open Tuberculosis in Police Custody Suites the Risks to those Working there and Current United Kingdom Public Health Legislation. J Forensic Res 2:129. doi:10.4172/2157-7145.1000129

Copyright: (c) 2011 Bruce-Chwatt RM. This is an open-access article distributed under the terms of the Creative Commons Attribution License, which permits unrestricted use, distribution, and reproduction in any medium, provided the original author and source are credited. 
He denied smoking heroin and crack together as a "snowball". On examination he had a deep cough and this raised the concern about the underlying TB infection and whether he was infectious. He was thin and looked unwell. Due to his sleepiness a blood sugar estimation was offered, but refused. He asked for methadone, which was refused, not wishing to depress him further.

He was put into a six hour rest period and, as a precaution, placed on 30 minute checks whilst further enquiries were made at King's College Hospital, London. The TB nurse at $\mathrm{KCH}$ said that he had been "lost to follow up" and that it was very likely that he was infectious. On a further telephone call, Dr R confirmed what had been said and that he was "very likely to have active TB". It was decided that he should be taken, as soon as possible, to $\mathrm{A} \& \mathrm{E}$ at $\mathrm{KCH}$ for an urgent chest $\mathrm{x}$-ray, a Ziehl-Neelson stain sputum test for acid fast bacilli (AFB) or, far better these days, a polymerase chain reaction (PCR) rapid test.

Since AV had not been very co-operative and would be wanting to buy more heroin, it was suggested that if TB was confirmed, they might consider asking a magistrate to order him to be held in hospital under s.37-38 of the Public Health Act $1984[3,4]$ until proven no longer infectious. The cell where he had been held would be sealed, pending the diagnosis [5]. The officers, who had been involved in arresting and looking after A.V. were told that provided that they had had a BCG, which they all believed they had, they should have no further concerns.

\section{Discussion}

AV's chaotic life style, in terms of his drug abuse, makes it very unlikely that, even if he wanted to, he would be chemo-compliant or co-operate with doctors and Public Health officials or be able to do so. The WHO, which declared TB a global emergency in 1992, now strongly advocates directly observed therapy (DOT) to ensure chemocompliance. AV's primary thoughts and judgement would be far more focused and aimed at his obtaining further supplies of illicit Class A drugs, rather than taking his anti-tubercular drugs. Due to his Class A drug habit he had absolutely no insight into his clinical condition, being completely reckless as to the risk that he posed to the general public. However, sections 37 and 38 of the Public Health (Control of Disease) Act 1984 do give powers for the removal to, and detention in, a suitable hospital for a person with a serious infectious disease. This are defined under the Act as a "notifiable disease". The list is, of course, only a basic guide, as there are conditions and exceptions. If it is thought that urgent action is required; it is advisable to check if a particular disease is notifiable under the legislation for the purposes of $\mathrm{s.37}$ and s.38, before taking any action that might afterwards prove unlawful, if nevertheless well meant. The following diseases are notifiable under the Act of 1984, of which Mycobacterium tuberculosis is now also one since the initial list was extended substantially in 1988 including: cholera, plague, relapsing fever, smallpox and typhus.

The list is extended by Schedule 1 to this Act and the Public Health (Infectious Diseases) Regulations 1988 (SI 1988/1546) to include diseases such as the following: Acquired immune deficiency syndrome (AIDS), acute encephalitis, acute meningitis, acute poliomyelitis, anthrax, diphtheria, dysentery (amoebic or bacillary), food poisoning (all sources), infective jaundice, lassa fever, leprosy, leptospirosis, malaria, Marburg disease, measles, meningococcal septicaemia (without meningitis), mumps, ophthalmia neonatorum (of Crédés prophytactic drops memory), paratyphoid fever, rabies, rubella, scarlet

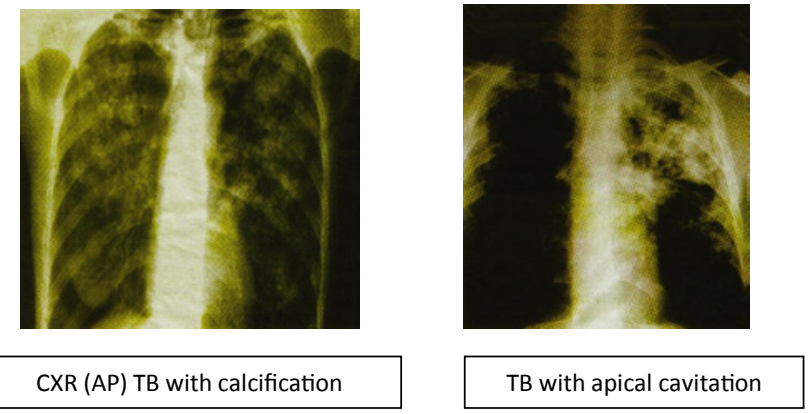

Figure 2: Examples of clinical TB on chest X-ray. (Roehampton Hospital X-ray museum).

fever, tetanus, tuberculosis, typhoid fever, viral haemorrhagic fever, viral hepatitis, whooping cough and yellow fever (Figure 2).

In application to AIDS, s.38 was modified by the Public Health (Infectious Diseases) Regulations 1988 (SI 1988/1546) (regulation 5) to give wider powers to magistrates. Where required a justice of the peace may, on the application of any local authority, make an order for the detention in hospital of an inmate of that hospital suffering from AIDS syndrome if the JP is satisfied that on his leaving the hospital proper precautions to prevent the spread of the disease would not be taken by him at his accommodation or in other places to which he may be expected to go.

\section{Removal to hospital of person with notifiable disease}

Where a justice of the peace (acting, if he deems it necessary, exparte) is satisfied, on the application of the local authority, that a person is suffering from a notifiable disease and that their circumstances are such that proper precautions to prevent the spread of infection cannot be taken, or that such precautions are not being taken, and there is a serious risk of infection to other people, and that accommodation for them is available in a suitable hospital, then the JP can order them to be removed there.

The police may be asked by health officials to be present whilst the infected person is detained by them to prevent a possible breach of the peace. Officers involved may well consult their Duty FME or local hospital infectious diseases unit as to the extent of the protection, physical and immunological, they may require, particularly if they are likely to be in a "roll around" with an individual who is unwilling to go with the officials peacefully. It may be that they should wear the same protection as the officials. Officers should bear in mind the possibility of being spat at, scratched or bitten, but this can occur during arrest whether the person has TB or not...

When arranging the transfer of the infected person, calm and reasoned communication is vital as they are likely to be frightened and confused, especially if English is not their mother tongue and many persons, from FME experience, even if they have been in the UK for even ten years, may speak little or no English. Every effort should, therefore, be made to take account of his or her circumstances and understanding of English.

Officers should again be careful not to act in any way which could be considered inhuman or degrading (Article 3, The Human Rights Act 1998). This is especially true with children or juveniles whose parents 
or guardians should be fully aware, informed and if possible, presents [6].

\section{Detention in hospital of person with notifiable disease}

As before, if a JP is satisfied that an inmate of the hospital who is suffering from a notifiable disease would not, on leaving the hospital, be provided with accommodation where proper precautions could be taken to prevent the spread of the disease, the JP may order them to be further detained in hospital for a specified period. Any person or patient leaving a hospital contrary to a detention order made under this section commits an offence and the court may well order them to be taken back to hospital. The powers of arrest under these circumstances are those of an Arrest without warrant, as an order from a magistrate being in force in any case, thus giving the health official extensive powers to detain the infected person. In the most dangerous forms of multidrug resistant TB, officer safety notices, as seen at Charing Cross police station, may be issued, though these do not seem include the power of arrest, but merely the power of persuasion, which is somewhat bizarre, if not idiotic.

\section{Historical notes and current treatment regimes}

First recognised and isolated by Dr Robert Koch (1843-1910) in 1882 cultured in a hanging droplet of ox aqueous humor, Mycobacterium tuberculosis, has managed to stay with us and, regrettably, even evolve to be multi-resistant. This despite evolutionary treatment and diagnosis via X-rays, Mantoux and Heaf tests, microscopy, ZeihlNeilson staining of sputum, surgical lung collapse, mass immunization by BCG, available for 75 years, (though not currently in use in the USA or Australia, where individual cases are treated and only selective BCG immunization in the UK), isolation, and modern day triple therapy [7].

Surgical excision had became possible when Ernst Ferdinand Sauerbruch (1875-1951) demonstrated the negative pressure cabinet in 1904 at Mikulicz' clinic at Breslau, Germany. This allowed the opening of the pleural cavity without the lungs collapsing. Professor Sauerbruch's name became linked to iatrogenisis as, in later life, he became demented, but continued to operate with fatal results. Colleagues aware of his errors felt unable to stop him because of his fame and power, echoes from the past ignored in the Bristol Royal Infirmary Heart Hospital scandal in 1995 and for similar reasons. $\mathrm{Mr}$ James Wisheart, a paediatric heart surgeon, had been allowed to carry on operating on babies and children despite repeated warnings of high death rates from an anesthetist.

Finally the GMC struck off Mr Wisheart in 1998 for serious professional misconduct. In the early part of the $20^{\text {th }}$ century, the "treatment" in Alpine sanatoria was in vogue. As yearly as 1902, a prototype, was built at Davos, Switzerland by Dr Karl Turban and the architect Jacques Gros. Others soon followed with Bohislav Fuchs' Radon Sanatorium [8].

These sanatoria were part hospital and part pension, where TB sufferers came to spend many months or years with a treatment of daily temperature checks, sunshine, mountain air, diet and gentle walks. In Thomas Mann's novel “The Magic Mountain”, [9] Hans Castorp is the sufferer from TB, whilst the dreadful, haemoptic finale for Patricia in "Three Comrades" by Erich Maria Remarque, of "All Quiet on the Western Front" fame, is less well known, though 'she died hard and no one could help her' $[10]$.
On the basis of "primum non nocere" and with no effective chemotherapy, the sanatoria did not improve the survival rates of their patients, but by isolating infectious patients, reduced transmission of $\mathrm{TB}$ in the general public; something that we risk again today in the UK from poor housing with poverty driven multi-occupancy, increasing undiagnosed $\mathrm{TB}$, ignorance, and non-compliance with long term chemotherapy. The fear of such patients of discovery as an illegal immigrant or a clandestine makes them invisible to the health services until they are arrested and the condition recognized by the FME. Those picked up are probably the tip of the TB iceberg in the UK.

Before the discovery of specific antibiotics for the treatment of TB, there was no cure and mortality, in the pulmonary form, was about $50 \%$. The introduction of anti-tuberculosis drugs in the early 1950 s meant that by the 1980s there was a $98 \%$ chance of cure; provided that treatment was continued with good quality drugs for as long six months. The first triple therapy with PAS (para-aminosalisylic acid) (late 1940s), isoniazid (1952) and streptomycin (1944) which then, with building drug resistance of DR-TB, became rifampicin, ethambutol and capreomycin in 1980's. Today MDR-TB (multi-drug resistant TB) is defined as being resistant to isoniazid and rifampicin, whether there is resistance to other drugs or not, but XDR-TB appears to be resistant to all. The FME should be aware of all the risk factors which may increase the probability of DR, MDR and XDR-TB and, amongst the type of patient that we see, the following are important risk factors for drug resistance: a) Immigration from an area with a high incidence of TB and of multi-drug resistance, b) HIV sero-positivity, c) Substance abuse, usually Class A, such as heroin and cocaine, d) Homelessness or with no fixed abode, e) Previous treatment for TB, especially if prolonged, and f) Contact with another patient known to have drug resistant TB.

For the Metropolitan police FME all, if not most, of these criteria define or are almost pathognomonic for a great many of our patients. Traditional confirmation of TB was by smear and culture, but is insensitive and slow, with only $50 \%$ of pulmonary tuberculosis positive on sputum and bacteria can take weeks to grow on culture medium. The latest polymerase chain reaction (PCR), a DNA augmentation method, rapidly multiplies the bacterial DNA, giving a "culture" result within hours. The new standard of regime for the treatment of tuberculosis has become isoniazid $(\mathrm{H})$, rifampicin $(\mathrm{R})$, and pyrazinamide $(\mathrm{Z})$ for two months followed by isoniazid and rifampicin for four months. This is conveniently abbreviated to 2HRZ/4HR. 6 idem For TB to have come back to the UK, and with such strength, is a salutatory lesson and a reminder that disease is an evolutionary matter, as well as disease of poor hygiene and dilapidated, over-crowded housing. The latest statistics [11] show slow improvement, but to take chemotherapy for granted and effective on its own, is to become complacent and risk repeating the errors of the past [12]. On March 212008 the report [13] of the first case in the UK of XDR-TB in a Somali asylum seeker is a matter of very great concern, not least for the 12-18 months and cost of $£ 100,000$ per patient to try to treat them.

\section{References}

1. Moszynski P (2007) Aid agencies fear for future of pastoralists in Horn of Africa BMJ 335: 958-959.

2. "Extra immigration checks urged at TB cases double", The Times, 21 April 2011.

3. Public Health (Control of Disease) Act, 1984, HMSO. 
Citation: Bruce-Chwatt RM (2011) Open Tuberculosis in Police Custody Suites, the Risks to those Working there and Current United Kingdom Public Health Legislation. J Forensic Res 2:129. doi:10.4172/2157-7145.1000129

4. Harris A, Martin R (2004) The exercise of public health powers in an era of human rights: the particular problems of tuberculosis. Public Health 118: 313322

5. Stark M, Rogers D, Norfolk G (2007) Good Practice Guidelines, London, MPS.

6. Human Rights Act (1998) article 3, London, HMSO.

7. Davies PDO M-DR TB Tuberculosis Research Unit, Liverpool L14 3PE.

8. Overy P (2008) Light, air and openness Thames and Hudson, London.
9. Mann T (1938) Der Zauberberg Alfred A. Knopf, New York, USA.

10. Remarque (1937) Erich Maria. Three Comrades Little, Brown \& Co Boston.

11. Zarocostas J (2008) British Medical Journal 336: 631

12. Burtt A, Davie S (2008) TB progress report (WHO), The Times.

13. Reid M (2008) Britain gets first case of untreatable TB, The Times. 